\title{
Atividade Antibacteriana de Frutas do Nordeste Brasileiro sobre Bactéria Cariogênica
}

\author{
Antibacterial Activity of Brazilian Northeast Fruits against Cariogenic Bacteria
}

\author{
Carlos Eduardo Mendes D'Angelis ${ }^{1}$ \\ Abner Nicolas da Silva ${ }^{2}$ \\ Nair Amélia Prates Barreto ${ }^{3}$ \\ Karina Andrade de Prince ${ }^{4}$ \\ Ana Cristina Carvalho Botelho ${ }^{5}$ \\ Ana Cristina Morseli Polizello ${ }^{6}$ \\ Augusto Cesar Cropanese Spadaro ${ }^{7}$
}

\begin{abstract}
Resumo: a cárie dentária é um grande problema de saúde pública em muitos países. Algumas regiões do Brasil são mais afetadas como o Norte e o Nordeste. A atividade antibacteriana frente à Streptococcus mutans representa um alvo terapêutico interessante para o estudo e controle da cárie dentária, já que este micro-organismo é reconhecido como um importante agente causador da formação de placa dental e cárie dentária. Objetivo: o objetivo deste trabalho foi avaliar a atividade antimicrobiana, frente à $S$. mutans, da polpa de frutos nativos da região Nordeste do Brasil: Spondias mombin L. (cajazeira), Spondias purpurea L (sirigueleira) e Spondias tuberosa (umbuzeiro). Metodologia: as frações clorofórmica, hexânica, acetato de etila e Aquosa de polpas de fruta integral dessas espécies foram obtidas através do processo de partição líquidolíquido. Realizou-se teste de difusão em ágar, caracterizando os extratos quanto ao seu potencial antimicrobiano frente à $S$. mutans, elegendo-se o de maior atividade para realização da concentração inibitória mínima - CIM. Resultados: as frações hexânica, acetato de etila e clorofórmica de cajá apresentaram expressiva atividade antimicrobiana frente a $S$. mutans nos ensaios de disco-difusão, sendo eleita para o teste de CIM. O teste revelou atividade inibitória de $0,01 \mathrm{mg} / \mathrm{mL}, 0,78 \mathrm{mg} / \mathrm{mL}$ e $0,02 \mathrm{mg} / \mathrm{mL}$ para as frações hexânica, clorofórmica e acetato de etila, respectivamente. Conclusão: conclui-se que as frações hexânica, clorofórmica e acetato
\end{abstract}

\footnotetext{
${ }^{1}$ Doutor em Ciências Farmacêuticas (FCFRP-USP). Professor da Universidade Estadual de Montes Claros (Unimontes). Minas Gerais. Brasil. $₫$ carlos.dangelis@ unimontes.br. (D) https://orcid.org/0000-0003-4792-6962

${ }^{2}$ Graduando de Medicina da Universidade Estadual de Montes Claros (Unimontes). Minas Gerais. Brasil. $\triangle$ abnernicolas@outlook.com.br. (D) https://orcid.org/0000-0001-8108-8750

${ }^{3}$ Mestre em Ensino em Ciências da Saúde (UNIFESP). Professora da Universidade Estadual de Montes Claros (Unimontes). Minas Gerais. Brasil. $₫$ nair.barreto@unimontes.br. (D) https://orcid.org/0000-0001-6036-252X

${ }^{4}$ Doutora em Biociências e Biotecnologia Aplicadas a Farmácia (UNESP). Professora do Centro Universitário FIPMoc - (UNIFIPMoc). Minas Gerais. Brasil. $₫$ karina.prince@bol.com.br. 10 https://orcid.org/0000-0001$\underline{8231-852 \mathrm{X}}$

${ }^{5}$ Doutora em Parasitologia (UFMG). Professora da Universidade Estadual de Montes Claros (Unimontes). Minas Gerais. Brasil. $₫$ anacristina.botelho@yahoo.com.br. (D) https://orcid.org/0000-0002-4143-605X

${ }^{6}$ Graduação em Ciências Biológicas (CUBM). São Paulo. Brasil. $\triangle$ anacrisp@ @ fcfrp.usp.br. https://orcid.org/0000-0001-5304-3942

${ }^{7}$ Livre Docência (USP). Professor da Faculdade de Ciências Farmacêuticas de Ribeirão Preto (FCFRP-USP).

São Paulo. Brasil. $₫$ cespada@usp.br. (D) https://orcid.org/0000-0003-2118-688X.
} 
de etila de cajá apresentaram interessante efeito antimicrobiano, principalmente as frações mais apolares, e, merecem estudos mais aprofundados quanto a sua atividade biológica.

Palavras-chave: Streptococcus mutans. Atividade antibacteriana. Produtos naturais.

Abstract: dental caries is a great public health problem in many countries. Some regions in Brazil are more affected as the North and Northeast. The antibacterial activity against Streptococcus mutans represent interesting therapeutic target for the study and control of the dental caries. S. mutans is known as the bacteria causing in dental plaque and dental caries formation. Objectives: the aim of this work was to evaluate the antimicrobial activity, against S. mutans, of the native fruits pulp from Brazilian Northeast area: Spondias mombin L. (cajazeira), Spondias purpurea L (sirigueleira). and Spondias tuberosa (umbuzeiro). Methodology: were evaluated the antimicrobial activity and the minimal inhibitory concentration (MIC) of the hexanic, chloroformic, ethyl acetate and aqueous fractions of the Spondias mombin L., Spondias purpurea L. and Spondias tuberosa extracts. The chloroform, hexane, ethyl acetate and aqueous fractions of whole fruit pulps of these species were obtained through the liquid-liquid partition process. A diffusion test was performed on agar characterizing the extracts as to their antimicrobial potential against $S$. mutans, being chosen the one with the highest activity for minimum inhibitory concentration (MIC). Results: the hexane, ethyl acetate and chloroform fractions of cajá presented significant antimicrobial activity against $S$. mutans in the disk-diffusion assays being chosen for the MIC test. The test revealed inhibitory activity of $0.01 \mathrm{mg} / \mathrm{mL}, 0.78 \mathrm{mg} / \mathrm{mL}$ and $0.02 \mathrm{mg} / \mathrm{mL}$ for the hexane, chloroform, and ethyl acetate fractions respectively. Conclusion: it was concluded that the hexane, chloroform and ethyl acetate fractions of cajá presented an interesting antimicrobial effect, mainly the more non-polar fractions, and deserve more detailed studies on their biological activity.

Key words: Streptococcus mutans. Antibacterial activity. Natural products.

\section{INTRODUÇÃO}

No Brasil, a saúde bucal está entre os três motivos principais para demanda em cuidados com a saúde, sendo a cárie dentária não tratada a condição de saúde bucal com maior prevalência. ${ }^{1,2}$ A cárie inicia-se com a adesão do $S$. mutans ao dente, sendo a principal bactéria envolvida pela sua capacidade de metabolizar uma variabilidade maior de carboidratos que qualquer outro gram-positivo. O S. mutans se estabelece em uma película de proteínas da saliva, iniciando a produção de um polissacarídeo aderente de glicose chamado dextrana, que forma a placa bacteriana pelo acúmulo de dextrana e bactérias na superfície do dente. Como a permeabilidade da placa à saliva é baixa. $\mathrm{O}$ ácido lático, produzido pelas bactérias, não é diluído ou neutralizado, o que resulta na desmineralização gradual do esmalte externo dos dentes e seu posterior rompimento, permitindo que bactérias penetrem em seu interior. ${ }^{3,4}$ 
A escovação e uso de fio dental, quando utilizados regularmente, são meios eficazes e seguros para remoção mecânica do biofilme. ${ }^{5}$ No entanto, esses métodos não são tão eficazes para diminuição de $S$. mutans de fissuras e superfícies proximais dos dentes, sendo assim, necessário o uso de agentes químicos como coadjuvantes da higienização bucal. ${ }^{6}$ Dentre os agentes químicos usados no controle da cárie dentária o que demonstrou maior eficácia foi a clorexidina. $^{7,8}$

Apesar da variedade de antibióticos desenvolvidos pela indústria farmacêutica, tem-se observado uma resistência, cada vez maior, das bactérias a essas drogas o que tem levado pesquisadores a buscarem alternativas em produtos naturais. ${ }^{7-11}$

Produtos farmacêuticos, a base de extrato vegetal, têm-se mostrado promissores por características como ausência de efeitos colaterais e baixo custo de produção, sendo especialmente importante em países de grande biodiversidade como o Brasil ${ }^{7,12,13}$.

O gênero Spondias pertence à família Anacardiaceae, podendo-se citar três espécies de destaque no Nordeste brasileiro: Spondias tuberosa Arr. (umbuzeiro), Spondias purpurea L. (sirigueleira), Spondias mombin L. (cajazeira). ${ }^{13}$

Estas árvores são frutíferas tropicais largamente exploradas através do extrativismo como a cajazeira e o umbuzeiro ou em pomares domésticos e em plantio desorganizados conduzidos empiricamente como a sirigueleira. Estas espécies produzem frutos de boa aparência, qualidade nutritiva, aroma e sabor agradáveis, os quais são muito apreciados para o consumo como fruta fresca ou na forma processada como polpa, sucos, doces, néctares, picolés e sorvetes. ${ }^{14}$

No Brasil, notadamente no Nordeste, estas espécies têm considerável importância social e econômica, fato comprovado pelo crescente processamento de seus frutos e comercialização dos produtos em mercados, supermercados e restaurantes da região. ${ }^{13}$

Este trabalho teve como objetivo realizar uma triagem do potencial anticariogênico dos extratos da polpa dos frutos das três espécies, elegendo uma para estudo mais criterioso quanto sua atividade antibacteriana sobre $S$. mutans. 


\section{METODOLOGIA}

\section{Origem e conservação das cepas}

Foram utilizadas cepas de S. mutans ATCC 25175, mantidas em caldo BHI (Brain Heart Infusion - Oxoid), enriquecido com glucose 1,0\% (p/v) e acrescido de glicerol 20,0\% (p/v), a $70^{\circ} \mathrm{C}$ até sua utilização.

\section{Obtenção dos extratos brutos}

Os frutos de Spondias mombin L. (cajazeira), Spondias purpurea L. (sirigueleira), Spondias tuberosa Arr. (umbuzeiro) foram obtidos no comércio local da cidade de Montes Claros/MG, na forma de polpa de fruta integral, comercializada pela Brasfrut ${ }^{\circledR}$. Duas embalagens Brasfrut ${ }^{\circledR}$, contendo $100 \mathrm{~g}$ cada uma, foram homogeneizadas e submetidas a secagem em estufa com ar circulante a $50^{\circ} \mathrm{C}$, durante 24 horas.

\section{Fracionamento do extrato bruto da polpa dos frutos, utilizando o processo de partição líquido-líquido}

Objetivando-se separar os seus componentes, o extrato bruto, de cada fruta, foi solubilizado em $300 \mathrm{~mL}$ metanol-água ${ }^{9}: 1(\mathrm{v} / \mathrm{v})$, filtrado e transferido para funil de separação e extraído com $300 \mathrm{~mL}$ de hexano. A fase hexânica foi transferida para balão de fundo redondo e concentrada em rotaevaporador sob pressão reduzida a $40^{\circ} \mathrm{C}$, sendo em seguida transferida para frasco, previamente pesado, e denominado fração hexânica.

A solução hidrometanólica restante foi rotaevaporada até eliminação do metanol e, em seguida, solubilizada em água destilada e particionada com $300 \mathrm{~mL}$ de clorofórmio. A fase clorofórmica foi transferida para balão de fundo redondo e concentrada em rotaevaporador sob pressão reduzida a $40^{\circ} \mathrm{C}$, sendo, em seguida, transferida para frasco, previamente pesado, e denominado fração clorofórmica. A solução aquosa remanescente foi particionada com $300 \mathrm{~mL}$ de acetato de etila, sendo concentrada até eliminação do solvente. O concentrado foi transferido para frasco, previamente pesado, e denominado fração acetato de etila. Finalmente, a solução restante foi liofilizada e denominada de fração aquosa. As frações obtidas foram pesadas e dissolvidas em Dimetilsulfóxido (DMSO) para se obter soluções estoque a $500 \mathrm{mg} / \mathrm{mL} .{ }^{11}$ 


\section{Disco difusão}

Foi realizado teste de sensibilidade de $S$. mutans, por meio de ensaio disco difusão em ágar, segundo metodologia padronizada. ${ }^{15}$ Para isso, foram preparadas soluções-estoque das frações obtidas em concentrações adequadas para que a transferência de $10 \mu \mathrm{L}$ de solução estoque resultasse em concentrações equivalentes a $1 \mathrm{mg} / \mathrm{disco}, 5 \mathrm{mg} / \mathrm{disco}$ e $10 \mathrm{mg} / \mathrm{disco}$. Discos estéreis e livres de antimicrobianos foram impregnados com as frações pelo depósito de $10 \mu \mathrm{L}$ das respectivas soluções-estoque. Um mililitro de cultura de S. mutans, cultivada em aerobiose, a $37^{\circ} \mathrm{C}$, durante 24 horas, em caldo $\mathrm{BHI}$, foi utilizada para preparação do inóculo. Com a utilização de um swab estéril, a suspensão bacteriana obtida foi inoculada, em 4 direções, em ágar BHI. Em seguida, o conjunto de discos impregnados foi colocado na superfície do ágar semeado. Como controle positivo, utilizou-se $6,7 \mu \mathrm{g}$ de base livre de clorexidina. Para excluir os efeitos inibitórios do DMSO, presente nas amostras, foi realizado um controle negativo com os seguintes volumes deste reagente: $1 \mu \mathrm{L}, 5 \mu \mathrm{L}, 10 \mu \mathrm{L}$ e $20 \mu \mathrm{L}$.

Foram testadas as seguintes frações:

a) Fração Hexânica de Cajá (FHC)

b) Fração Clorofórmica de Cajá (FCC)

c) Fração Acetato de etila de Cajá (FAeC)

d) Fração Aquosa de Cajá (FAC)

e) Fração Hexânica de Siriguela (FHS)

f) Fração Clorofórmica de Siriguela (FCS)

g) Fração Acetato de etila de Siriguela (FAeS)

h) Fração Aquosa de Siriguela (FAS)

i) Fração Hexânica de Umbu (FHU)

j) Fração Clorofórmica de Umbu (FCU)

k) Fração Acetato de etila de Umbu (FAeU)

1) Fração Aquosa de Umbu (FAU) 


\section{Determinação da concentração inibitória mínima - CIM das frações do extrato da polpa de Cajá sobre o crescimento de $S$. mutans in vitro}

Como todas as frações de extrato da polpa de Cajá apresentaram formação de halos ao redor dos discos, o que não ocorreu com os extratos de umbu e siriguela, o cajá foi selecionado para ter a sua concentração inibitória mínima - CIM, determinada nos demais testes de caracterização. Determinou-se a CIM das frações do extrato da polpa de cajá sobre o crescimento $S$. mutans in vitro, utilizando-se microplacas de cultivo com 96 cavidades em virtude de sua sensibilidade, simplicidade de execução e rapidez. ${ }^{16}$

Microplacas de 96 cavidades foram utilizadas para o ensaio, onde foram realizadas diluições seriadas das frações do extrato da polpa de cajá em caldo BHI. O controle positivo consistiu de uma sequência de cavidades com diluições seriadas de digluconato de clorexidina na faixa de concentração de 0,1 a 1,0 $\mu \mathrm{g} / \mathrm{mL}$. Para excluir o efeito inibitório de DMSO presente nas frações, realizaram-se diluições de DMSO nas mesmas proporções encontradas em cada diluição das frações do extrato da polpa de cajá. Todas as cavidades, contendo diluições seriadas dos extratos ou digluconato de clorexidina, foram inoculadas com $10^{4}$ UFC de $S$. mutans e incubadas a $37^{\circ} \mathrm{C}$ por 24 horas, em câmara úmida. $\mathrm{O}$ volume final em cada cavidade foi de 200 $\mu \mathrm{L}$. Controles de crescimento da cultura foram preparados apenas com o meio de cultura BHI e o inóculo de células.

Após o período de incubação, adicionou-se a cada cavidade $50 \mu \mathrm{L}$ de uma solução aquosa do sal nitroazul-tetrazólio $0,14 \%(\mathrm{p} / \mathrm{v})$ para se obter uma concentração final igual a 0,04\% . Após um breve período de incubação a $37^{\circ} \mathrm{C}$, o crescimento de $S$. mutans foi indicado pela coloração azul do derivado de formazan, produzido pela metabolização bacteriana do sal de tetrazólio ${ }^{16}$.

\section{RESULTADOS E DISCUSSÃO}

Não foi observada a formação de halos ao redor dos discos contendo diluições das frações hexânica, clorofórmica, acetato de etila e aquosa de umbú e siriguela. Portanto, não se detectou atividade antimicrobiana nestas frações, através deste método. No entanto, as frações FHC e FCC apresentaram notável atividade inibitória frente a $S$. mutans como mostra a figura 
1. A inibição do crescimento apresentou-se homogênea, de acordo com o grau de concentração das frações. Houve diminuição proporcional do diâmetro dos halos de inibição à medida que a concentração da fração foi diminuída. A fração hexânica de cajá FHC revelou atividade inibitória desde a menor concentração testada, apresentando halos de $12 \mathrm{~mm}, 14 \mathrm{~mm}$ e $17 \mathrm{~mm}$ paras as concentrações $1 \mathrm{mg} /$ disco, $5 \mathrm{mg} /$ disco e $10 \mathrm{mg} /$ disco, respectivamente. Já a fração clorofórmica de cajá FCC na concentração $1 \mathrm{mg} /$, não mostrou atividade antimicrobiana. Entretanto, nas concentrações $5 \mathrm{mg} /$ disco e $10 \mathrm{mg} /$ disco os halos de inibição foram de $12 \mathrm{~mm}$ e $16 \mathrm{~mm}$, respectivamente. A fração FAEC, também, apresentou atividade inibitória frente a $S$. mutans (Figura 2). A atividade antibacteriana foi detectada desde a menor concentração testada, apresentando halos de $10 \mathrm{~mm}, 12 \mathrm{~mm}$ e $15 \mathrm{~mm}$ paras as concentrações $1 \mathrm{mg} / \mathrm{disco}, 5$ mg/disco e $10 \mathrm{mg} /$ disco, respectivamente. Já a fração $\mathrm{FAC}$, não mostrou atividade antimicrobiana (Figura 2) em nenhuma das concentrações testadas $1 \mathrm{mg} / \mathrm{disco}, 5 \mathrm{mg} / \mathrm{disco}$ e 10 $\mathrm{mg}$ /disco. Esses achados sugerem que as frações FHC, FCC e FAEC possuem compostos bioativos com atividade antimicrobiana in vitro sobre as cepas de $S$. mutans.

Neste estudo, utilizamos como controle positivo, discos contendo $6,7 \mu \mathrm{g}$ de base livre de clorexidina. O diâmetro médio do halo, desse controle, foi de $27 \mathrm{~mm}$. Como controle negativo, foi utilizado DMSO que é o veículo utilizado para solubilizar as frações. Para isso, utilizamos concentrações desse solvente equivalentes ou superiores aquelas encontradas nas soluções estoque das frações testadas. Nas condições estudadas, o resultado do controle negativo revelou que DMSO não tem atividade inibitória sobre $S$. mutans, quando testado pelo método de disco-difusão.

A influência dos solventes (hexano, clorofórmio e acetato de etila), utilizados como veículo extratores nas partições, foi descartada, já que os processos extrativos foram realizados cuidadosamente, utilizando-se solventes grau analítico e previamente destilados. Outras frações, como FHS, FCS, FAeS, FAS, FHU, FCU, FAeU e FAU, não apresentaram atividade biológica nos ensaios de sensibilidade de $S$. mutans por disco-difusão, o que anula o efeito destes solventes, que são totalmente eliminados por evaporação previamente.

A técnica de difusão em ágar para os ensaios de atividade antimicrobiana é bastante difundida. $\mathrm{O}$ monitoramento deste tipo de atividade em produtos naturais, seja de origem microbiológica ou vegetal, é muito útil para se projetar o isolamento de novas estruturas químicas com potencial de utilização pela indústria farmacêutica ${ }^{17}$.

Considerando os resultados obtidos até o momento e a proposta do presente trabalho em identificar propriedades anticariogênicas em extratos das frutas de umbu, siriguela e cajá, 
verificou-se que as frações mais apolares FHC e FCC, sobretudo a fração hexânica, forneceram dados interessantes que merecem estudos mais aprofundados quanto a sua atividade biológica.

Apesar da imensa variedade de antibióticos desenvolvidos pelas indústrias farmacêuticas e químicas, nos últimos anos, cada vez mais tem sido observado um aumento da resistência das bactérias às drogas usadas para fins terapêuticos. Este fato tem levado pesquisadores de diversas áreas a buscarem alternativas em produtos naturais empregados na medicina popular de diversas regiões do mundo ${ }^{10,11,19,20}$.

Para determinação da CIM de cada uma das frações, foram feitos ensaios de sensibilidade de microdiluição em caldo. Esses ensaios foram feitos seguindo as recomendações da NCCLS $(2003)^{18}$. A leitura foi realizada através da mudança de cor da solução reveladora NBT, considerando o resultado positivo a ausência de coloração e negativo na presença de coloração azulada.

A fração hexânica de cajá FHC apresentou CIM de 0,01 mg/mL. A CIM para fração clorofórmica de cajá FCC foi igual a $0,78 \mathrm{mg} / \mathrm{mL}$. A fração acetato de etila de cajá a CIM foi igual a 0,02 mg/mL, e, a fração aquosa de cajá FAC não apresentou CIM nas concentrações testadas.

A Figura 3 apresenta fotografias digitais da placa de microcultivo para a determinação da CIM das frações FHC, FCC, FAEC e FAC.

Os principais grupos de compostos com atividade biológica, extraídos de plantas e presentes nestas frações incluem terpenóides e óleos essenciais, alcalóides, lectinas e polipeptídios, bem como, substâncias fenólicas e polifenóis, que são os fenóis simples, ácidos fenólicos, as quinonas, flavonóides, taninos e cumarinas ${ }^{21}$.

Produtos farmacêuticos, a base de extrato vegetal, são promissores visto as vantagens oferecidas, como ausência de efeitos colaterais e baixo custo de produção, fatores estes de fundamental importância para o seu uso e aplicação. Entre as propriedades farmacológicas citadas tem-se a antimicrobiana, anti-inflamatória e citostáticas, dentre outras ${ }^{19,20}$.

As possibilidades de aplicação de produtos naturais são citadas tanto na indústria quanto na odontologia, apresentando atividade frente a várias bactérias gram-positivas e gramnegativas. Alguns produtos já foram reportados como novos candidatos a substâncias anticariogênicas por inibir o crescimento de $S$. mutans ou pela inibição de glucosiltransferases. Porém, pela elevada prevalência da cárie é evidente que estes agentes não são suficientemente efetivos, indicando a necessidade do desenvolvimento de novos agentes preventivos para cárie $\operatorname{dental}^{7,21,22}$ 
Os produtos naturais fazem parte de um campo de investigação com infinito potencial, sendo especialmente importante em países com grande biodiversidade, como Brasil ${ }^{23}$. O presente estudo apresenta o potencial de ação antibacteriano dos extratos da polpa de cajá, produto nativo do semiárido da região Nordeste brasileira. A sua importância está no sentido de estudar e conhecer as atividades biológicas destes frutos, ainda pouco explorados, quanto ao seu potencial de diminuição dos efeitos danosos da cárie, podendo representar uma importante contribuição para a saúde bucal da população do país.

Os achados deste estudo destacam que um dos extratos da polpa de cajá apresenta atividade antibacteriana interessante e promissora contra a principal bactéria cariogênica $S$. mutans.

\section{CONCLUSÃO}

Concluiu-se, portanto, que as frações Fração Aquosa de Cajá, Fração Hexânica de Siriguela, Fração Clorofórmica de Siriguela, Fração Acetato de etila de Siriguela, Fração Aquosa de Siriguela, Fração Hexânica de Umbu, Fração Clorofórmica de Umbu, Fração Acetato de etila de Umbu, Fração Aquosa de Umbu não apresentaram atividade inibitória nos testes de sensibilidade $S$. mutans por ensaio de disco-difusão. Já as frações Fração Hexânica de Cajá, Fração Acetato de etila de Cajá e Fração Clorofórmica de Cajá apresentaram expressiva atividade antimicrobiana frente a $S$. mutans nos ensaios de disco-difusão, sendo eleita para os demais testes de caracterização, obtendo valores de CIM para Fração Hexânica de Cajá, Fração Clorofórmica de Cajá e Fração Acetato de etila de Cajá de 0,01 mg/mL, 0,78 mg/mL e 0,02 $\mathrm{mg} / \mathrm{mL}$, respectivamente. Observou-se, também, que as frações mais apolares, Fração Hexânica de Cajá e Fração Clorofórmica de Cajá, sobretudo a fração hexânica, forneceram dados interessantes que merecem estudos mais aprofundados quanto a sua atividade biológica.

\section{REFERÊNCIAS}

1. INSTITUTO BRASILEIRO DE GEOGRAFIA E ESTATÍSTICA. Um panorama da saúde no Brasil: acesso e utilização dos serviços, condições de saúde e fatores de risco e proteção à saúde 2008. Disponível em: http://www.ibge.gov.br/home/estatistica/populacao/panorama_saude_brasil_2003_2008/.Aces so em: 23 de Abril de 2018.

2. KASSEBAUM, N. J. et al. Global burden of untreated caries: a systematic review and metaregression. J Dent Res., Thousand Oaks, v. 94, n. 5, p. 650-658, mar, 2015. 
3. COTA, A. L. S., ALVIM, R. G. Effect of storage temperature on Streptococcus mutans viability. Rev. odontol. UNESP, Araraquara, v. 47, n. 2, 2018.

4. FORSSTEN S. F., BJÖRKLUND M., OUWEHAND A. C. Streptococcus mutans, Caries and Simulation Models. Nutrients, Suíça, v. 2, n. 3, p. 290-298, mar, 2010.

5. AXELSSON P., LINDHE J., WÄSEBY J. The effect of various plaque control measures on gingivitis and caries in schoolchildren. Community Dentistry And Oral Epidemiology. Copenhaguen, v. 4, n. 6, p. 232-239, nov, 1976.

6. LEMES, R. S. et al . Chemical composition and antibacterial activity of essential oils from Citrus aurantifolia leaves and fruit peel against oral pathogenic bacteria. An. Acad. Bras. Ciênc., v. 90, n. 2, 2018.

7. ALMEIDA B. S., BASTOS J. R. M. Uso de clorexidina associada com a escovação no controle de placa dentária de escolares. Revista Gaúcha de Odontologia, Campinas, v. 49, n. 3, p. 133-138, 2001.

8. WANG H., REN D. Controlling Streptococcus mutans and Staphylococcus aureus biofilms with direct current and chlorhexidine, AMB Express, Heidelberg, v. 7, n. 1, p. 204, nov, 2017.

9. OOSHIMA T. et al. Caries inhbitory activity of cacao bean husk extract in in-vitro and animal experiments, Archives of Oral Biology, Oxford, v. 45, n. 8, p. 639-645, ago, 2000.

10. LEITÃO D. P. S. et al. Comparative Evaluation of in-Vitro Effects of Brazilian Green Propolis and Baccharis dracunculifolia Extracts on Cariogenic Factors of Streptococcus mutans. Biol. Pharm. Bull., Tókio, v. 27, n. 11, p. 1834-1839, nov, 2004.

11. LEITÃO D. P. S. et al. Antibacterial Screening of Anthocyanic and Proanthocyanic Fractions from Cranberry Juice. Journal of Medicinal Food, Larchmont, v. 8, n. 1, p. 36-40, abr, 2005.

12. I.J.O. Sousa, et al. A diversidade da flora brasileira no desenvolvimento de recursos de saúde. Revista UNINGÁ Review, Maringá, v. 31, n. 1, p. 35-39, jul-set, 2017.

13. SILVA C. G. et al. Evaluation of antioxidant activity of Brazilian plants. Pharmacol. Res., Londres, v. 52, n. 3, p. 229-233, set, 2005.

14. ALVES R. E., FILGUEIRAS H. A. C., MOURA C. F. H. Caracterização de frutas nativas da América Latina. Jaboticabal: Funep, 2000.

15. Clinical and Laboratory Standards Institute - NCCLS. Performance standards for antimicrobial susceptibility testing. Fiftheent Informational Supplement. CLSI/NCCLS document M100-S15 [ISBN 1-56238-556-9].

16. ELOFF J. N. A sensitive and quick microplate method to determine the minimal inhibitory concentration of plant extracts for bacteria. Planta Med., Stuttgart, v. 64, n. 8, p. 711-713, dez, 1998. 
17. D'ANGELIS, C. E. M.; LEITE, M. F.; SOUSA, J .P .B.; ALONSO, L.; POLIZELLO, A. C. M.; AIRES, C. P.; BASTOS, J. K.; GROPPO, M.;; SPADARO, A. C. C. Inhibiting effect of Dorstenia asaroides extracts on cariogenic properties of Streptococcus mutans. Anaerobe. v.18, n.1, p. 31-36, 2012. http://doi:10.1016/j.anaerobe.2011.12.020.

18. NCCLS. Methods for dilution antimicrobial susceptibility tests for bacteria that grow aerobically: approved standard. 6ed. Wayne, PA: Technical Report M07-A6, 2003.

19. WU-YUAN, C. D.; GREEN, L; BIRCH, W. X. In vivo screening of Chinese medicinal toothpastes: their effects on growth and plaque formation of mutans streptococci. Caries Res., v. 24, p. 198-202, 1990.

20. OOSHIMA, T.; OSAKA, Y.; SAZAKI, H.; OSAWA, K.; YASUDA, H.; MATSUMURA, M.; SOBUE, S.; MATSUMOTO, M. Caries inhibitory effect of cacao bean husk extract in in vitro and animal experiments. Arch. Oral. Biol., v. 45, p. 639-643, 2000.

21. FERRAZZANO, G. F., SCIOSCIA, E., SATERIALE, D., PASTORE, G., COLICCHIO, R., PAGLIUCA, C., CANTILE, T., ALCIDI, B., CODA, M., INGENITO, A., SCAGLIONE, E., CICATIELLO, A., VOLPE, M. G., DI STASIO, M., SALVATORE, P., PAGLIARULO, C. In vitro antibacterial activity of pomegranate juice and peel extracts on cariogenic bacteria. Biomed Res Int. 2017. https://doi.org/10.1155/2017/2152749.

22. RAJA MAZLAN, R. N. A., RUKAYADI, Y., MAULIDIANI, M., ISMAIL, I. S. Solvent extraction and identification of active anticariogenic metabolites in Piper cubeba L. through ${ }^{1}$ H-NMR-based metabolomics approach. Molecules, v. 16, n. 23, 2018.

23. BARNABÉ, M., SARACENI, C. H., DUTRA-CORREA, M., SUFFREDINI, I. B. The influence of Brazilian plant extracts on Streptococcus mutans biofilm. J Appl Oral Sci, v. 22, n. 5, 2014. 